\title{
Article \\ The Negative Photoconductivity of Ag/AgO Grown by Spray-Pyrolysis
}

\author{
Aline Bastos de Paiva ${ }^{1}{ }^{1}$, Luis Miguel Bolaños Vargas ${ }^{2}$, Matheus José da Silva ${ }^{2}$, \\ Ariano De Giovanni Rodrigues ${ }^{1} \mathbb{D}$, Demétrio A. W. Soares ${ }^{2}$, Marcelos Lima Peres ${ }^{2} \mathbb{D}$ \\ and Marcio Peron Franco de Godoy ${ }^{1, *}$ \\ 1 Departamento de Física, Universidade Federal de São Carlos, São Carlos 13565-905, SP, Brazil; \\ aline.paiva.fisica@gmail.com (A.B.d.P.); ariano@df.ufscar.br (A.D.G.R.) \\ 2 Instituto de Física e Química, Universidade Federal de Itajuba, Itajubá 37500-903, MG, Brazil; \\ luis_fis_86@unifei.edu.br (L.M.B.V.); matheusjsilva@unifei.edu.br (M.J.d.S.); werner@unifei.edu.br (D.A.W.S.); \\ marcelos@unifei.edu.br (M.L.P.) \\ * Correspondence: mgodoy@ufscar.br
}

check for updates

Citation: de Paiva, A.B.; Vargas, L.M.B.; da Silva, M.J.; Rodrigues, A.D.G.; Soares, D.A.W.; Peres, M.L.; de Godoy, M.P.F. The Negative Photoconductivity of $\mathrm{Ag} / \mathrm{AgO}$ Grown by Spray-Pyrolysis. Surfaces 2022, 5, 209-217. https://doi.org/

Academic Editor: Gaetano Granozzi

Received: 22 January 2022

Accepted: 24 February 2022

Published: 2 March 2022

Publisher's Note: MDPI stays neutral with regard to jurisdictional claims in published maps and institutional affiliations.

Copyright: (C) 2022 by the authors. Licensee MDPI, Basel, Switzerland. This article is an open access article distributed under the terms and conditions of the Creative Commons Attribution (CC BY) license (https:// creativecommons.org/licenses/by/ $4.0 /)$.

\begin{abstract}
The main goal of this work is to provide a general description of the negative photoconductivity effect observed in $\mathrm{Ag} / \mathrm{AgO}$ films grown by the spray-pyrolysis technique. X-ray diffractograms display hybrid films with high texturized $\mathrm{AgO}$ and metallic Ag phases. Scanning electron microscopy images show small Ag particles on the surface. Due to its surface nature, X-ray photoelectron spectroscopy revealed the predominance of the metallic character of Ag 3d spectra as compared to $\mathrm{Ag}^{2+}$. Negative photoconductivity with photoresponse in the order of seconds is observed under several wavelengths of excitation. We found that the amplitude of the negative photoresponse is strongly dependent on the optical absorbance and enhanced by surface plasmon resonance. The low-cost technique employed and the special features regarding negative photoconductivity provide an exciting platform for developing optical-electronic devices with low power consumption.
\end{abstract}

Keywords: oxides; photoconductivity; silver; surface plasmon resonance

\section{Introduction}

Metal oxides films present exciting features such as the semiconductor behavior and optical transparency associated with several ways to synthesize them. The high reactivity of oxygen bounds is also attractive to develop surface-based devices such as gas and liquid sensors [1,2]. In addition, the surface decoration with noble metal structures is a powerful tool to enhance sensing response in light-assisted devices [3]. In such a case, the use of Ag structures increases the local electromagnetic field by surface plasma absorbance that strengthens hot electron-based processes important to photochemical reactions [4]. Regarding Ag-based nanostructures, Ag nanoparticles and Ag nanowires are well employed in chemical engineering, aerospace, medicine, and electronics. Particularly, the Ag nanowires are good candidates to replace indium tin oxide (ITO) in several applications [5,6]. Additionally, the introduction of metallic nanoparticles in thin films would have a drastic influence on the mechanical and optoelectronic properties of electro-optical devices opening the possibility of improvement or development of sensor devices in a wide range of applications including plasmonics and photocatalysis phenomena [7-9]. In addition, metallic nanoparticles allow the fabrication of stretchable conductive thin films due to their mechanical properties that includes greater flexibility. This is important for thin films electrodes on plastic substrates, for example. A complete review of the type and importance of metallic nanoparticles in thin films for new optic-electronic devices is provided in reference [10]. Besides nanostructures, silver oxides have many technological applications as electrodes for batteries and photocatalytic degradation systems for pollutants [11-13]. 
Although the electrical and optical properties are being employed in current applications, the literature misses reports about the photoconductivity of silver oxides, restricted to the conventional positive photoresponse $[14,15]$ with the increase in conductivity under illumination. In contrast, negative photoconductivity (NPC), which presents a decrease in electrical conductivity in the presence of light, also emerges as an exciting mechanism to be applied in photodetection and nonvolatile memory that requires low power consumption $[16,17]$.

Due to its d-shell configuration, many oxidation states give rise to several oxides such as $\mathrm{Ag}_{2} \mathrm{O}_{3}, \mathrm{Ag}_{3} \mathrm{O}, \mathrm{Ag}_{2} \mathrm{O}$, and $\mathrm{AgO}$, depending on the growth conditions, mainly the reaction kinetics and the availability of oxygen required for the oxidation. Furthermore, controlled oxidation of Ag for a large-scale process is still a challenge. Among many physical and chemical processes, spray pyrolysis (SP) seems a suitable technique to produce hybrid films of silver oxides employing the process of silver acetate decomposition and oxidation at moderated temperatures [11]. This process is a hybrid method based on the evaporation of solvent followed by the pyrolysis of solute. A fundamental issue is the quantity of the available precursor molecules present in the micrometric droplets employed to form a film or a coating.

This investigation presents the synthesis of $\mathrm{Ag} / \mathrm{AgO}$ hybrid thin films grown by spray pyrolysis and their structural and optical-electrical characterization. The experimental data reveal a well-textured $\mathrm{AgO}$ thin film with the presence of an $\mathrm{Ag}$ metallic phase on the surface. Under illumination, the electrical conductivity decreases for excitations of several wavelengths in the visible range. A decrease in the negative photoconductivity, followed by an increment in response times, is observed when the wavelengths match the range of plasmon absorbance of the $\mathrm{Ag}$ phase.

\section{Materials and Methods}

Silver oxide thin film was grown on a soda-lime substrate with spray pyrolysis technique, presenting versatility and economic viability. Figure 1 displays the setup consisting of an atomizer fed by a carrier gas (dry compressed air) at $0.1 \mathrm{MPa}$ and a pumped liquid precursor solution. Considering the definition of molarity (M) as the solute number of mols in a volume of 1 liter, the low molarity $(\mathrm{M})$ precursor solution $\left(\mathrm{M}=4 \times 10^{-3} \mathrm{~mol} / \mathrm{L}\right)$ consists of solid silver nitrate $\left(\mathrm{AgNO}_{3}\right.$ by Synth, with a molar mass of $\left.169.87 \mathrm{~g} / \mathrm{mol}\right)$ as solute diluted in distilled water. The growth is based on cycles described elsewhere [18], and the low molarity condition tends to increase the crystallinity of films grown by spray pyrolysis [19]. Each cycle has duration of $2 \mathrm{~min}$, and the growth starts with the deposition of layers at $300{ }^{\circ} \mathrm{C}$ by atomized microdroplets formed in a precursor flux of $0.25 \mathrm{~mL} / \mathrm{min}$. During this period, the substrate temperature drops up to $220^{\circ} \mathrm{C}$ when the spraying is interrupted. The substrate temperature increases to $300^{\circ} \mathrm{C}$, and a new cycle starts. This temperature range is enough to break silver nitrate molecules and form nucleation zones at the substrate. The typical number of cycles is 20.

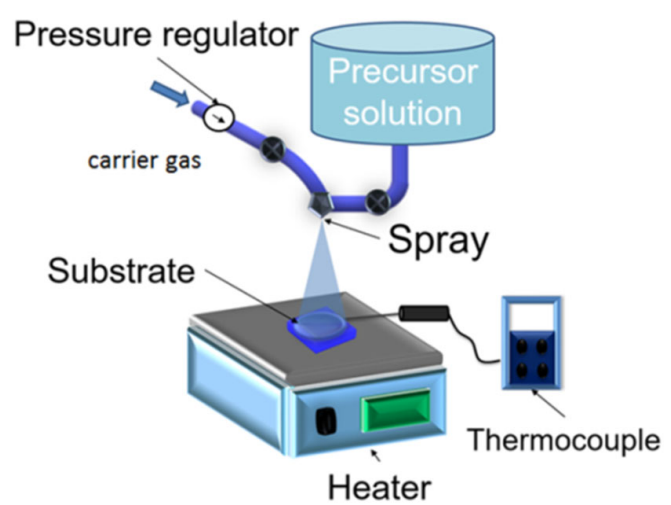

Figure 1. Experimental setup employed to grow oxide thin films at low molarity conditions. 
The crystallographic structure and phases were analyzed using a Shimadzu X-ray diffractometer (XRD-6100) (Shimadzu Corp., Kyoto, Japan) with $\mathrm{Cu}-\mathrm{K}_{\alpha}$ radiation $(\lambda=1.5406 \AA)$ in the range of $10-90{ }^{\circ} \mathrm{C}$ with a step size of $0.2^{\circ} / \mathrm{min}$. A JEOL JSM 5800 LV microscope (JEOL, Tokyo, Japan) performed scanning electron microscopy images (SEM). The optical transmittance was analyzed with a spectrophotometer Agilent Cary 5000 UV-VIS-NIR (Agilent Co., Santa Clara, CA, USA) in the range 200-1200 nm at room temperature. X-ray photoelectron spectroscopy (XPS) employed a ThermoScientific KAlpha spectrometer (Thermo Fisher Scientific, Waltham, MA, USA) using Al-K $\alpha(1486.6 \mathrm{eV})$ radiation at Brazilian Nanotechnology National Laboratory (LNNano/CNPEM). Using Shirley's baseline, the spectra were corrected on C 1s $(284.8 \mathrm{eV})$ and analyzed by CasaXPS software (Casa Software Ltd., Teignmouth, UK). The photoconductivity was evaluated by measuring the voltage changes by a Keithley 2001 multimeter (Keithley, Cleveland, $\mathrm{OH}, \mathrm{USA}$ ) when a Keithley 237 source applies a constant electrical current of $1 \mathrm{nA}$. The illumination was provided by different light-emitting diodes (LEDs): ultraviolet (400 nm$3.10 \mathrm{eV})$, blue $(477 \mathrm{~nm}-2.60 \mathrm{eV})$, green $(533 \mathrm{~nm}-2.33 \mathrm{eV})$, yellow $(591 \mathrm{~nm}-2.10 \mathrm{eV})$, and red $(634 \mathrm{~nm}-1.95 \mathrm{eV})$.

\section{Results and Discussion}

\subsection{Structural Characterization}

The characterization by X-rays (XRD) shows well-defined diffraction peaks at $32.25^{\circ}$, $38.12^{\circ}, 44.17^{\circ}$ and weak peaks at $64.45^{\circ}$ and $67.40^{\circ}$ in Figure 2. The most intense peak at $32.25^{\circ}$ is associated with monoclinic $\mathrm{AgO}$ (JCPDS 43-1038), far enough to exclude $\mathrm{Ag}_{2} \mathrm{O}$ phases (hexagonal-JCPDS 72-2108 and cubic-JCPDS 41-1104) up to the limit of detection. Applying Bragg law $\left(d_{\mathrm{hkl}}=\frac{\lambda}{2 \sin \theta}\right)$, the AgO interplanar is $\mathrm{d}_{111}=(1.443 \pm 0.001) \AA$. The other peaks are attributed to the cubic metallic silver (JCPDS 04-0783) phase. The calculated interplanar distances for a non-deformed Ag crystal are $\mathrm{d}_{111}=(2.359 \pm 0.001) \AA$ and $\mathrm{d}_{200}=(1.443 \pm 0.001) \AA$, which corresponds to the lattice parameter $\mathrm{a}=4.086 \AA$ of cubic metallic silver (JCPDS 04-0783). There is no evidence of texturization for metallic Ag meanwhile, and it is worth noting the texturization for the $\mathrm{AgO}$ phase at $\langle 111\rangle$ direction.

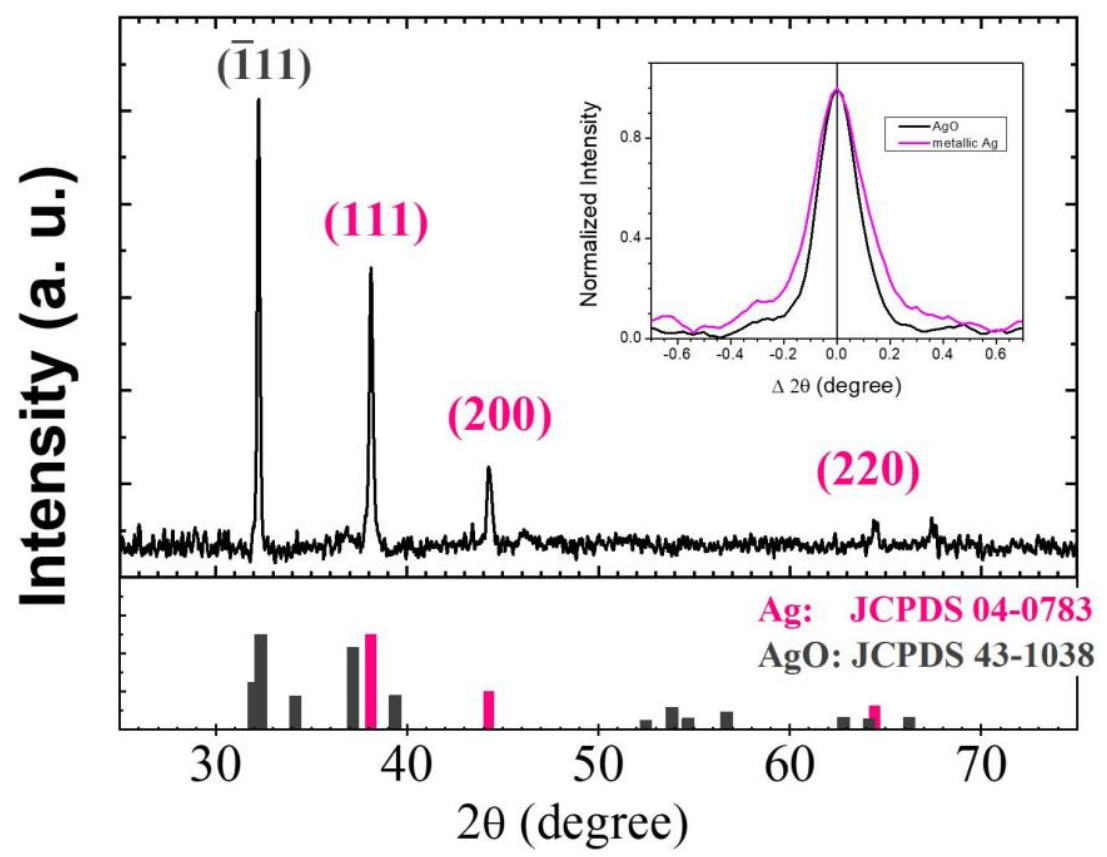

Figure 2. X-ray diffraction exhibits polycrystalline metallic Ag and high texturized AgO phases-the inset attests to the higher crystallinity of the AgO phase. 
The crystallinity and texturization of $\mathrm{AgO}$ film are remarkable, considering the relative simplicity and rapidity of the growth technique. The inset attests to the higher crystallinity of the AgO phase by comparing the relative width of main peaks. Crystallite sizes, obtained by the Scherrer equation [20], are $49.3 \mathrm{~nm}$ and $39.4 \mathrm{~nm}$ for AgO and metallic Ag at (111), respectively. Usually, physical and chemical deposition techniques evidence the dependence on growth conditions to achieve $\mathrm{AgO}, \mathrm{Ag}_{2} \mathrm{O}$, and metallic $\mathrm{Ag}$ phases. For instance, sputtering provides either amorphous films [21], AgO films [22], and Ag-embedded nanocrystallites [23], while chemical routes privilege the formation of AgO followed by $\mathrm{Ag}_{2} \mathrm{O}$ and $\mathrm{Ag}$ if subjected to annealing [24] or in oxygen-rich conditions in case of pulsed laser deposition [25]. Alternatively, the spray pyrolysis technique is a quasi-chemical vapor deposition process when it employs a low molarity precursor solution. The low content of solid precursors in the interior of water microdroplets breaks during solvent evaporation near or on the heated substrate, and nucleation centers are formed on top of the substrate, which could induce some orientation.

In contrast, for higher molarities, the layers present a powder-like character. In the case of zinc oxide, we recently demonstrated the influence of low molarities in the growth of transparent thin films, which are well oriented at the c-axis even in an amorphous substrate, such as soda-lime glass [19]. In addition, the technique enables the formation of doped layers and alloys with Cd, Co, or Mn $[18,26,27]$ in systematic and reproducible processes. For the $\mathrm{Ag} / \mathrm{AgO}$ film obtained by spray-pyrolysis, a possible growth route is considered if the dissociation of silver nitrate obeys $\mathrm{AgNO}_{3} \rightarrow \mathrm{AgO}+\frac{1}{2} \mathrm{~N}_{2}+\mathrm{O}_{2}$ in such a way that an aqueous vapor atmosphere near the substrate favors a stoichiometric relation with $\mathrm{Ag}^{2+}$ rather than $\mathrm{Ag}^{1+}$, which occurs in a deficient oxygen environment. Furthermore, there is a tendency to form metallic Ag clusters, as clearly observed in XRD characterization. However, further investigations are required to understand the complete overview considering other parameters such as growth temperature and annealing procedures.

The SEM overview reveals a pallet-like film with the presence of grooves, as noted in Figure 3a. Small cubic silver microstructures with sizes in the range of micrometers are clear for higher amplification (Figure 3b,c). The SEM images corroborate that the metallic Ag phase observed in XRD characterization is due to these structures rather than embedded clustered Ag.

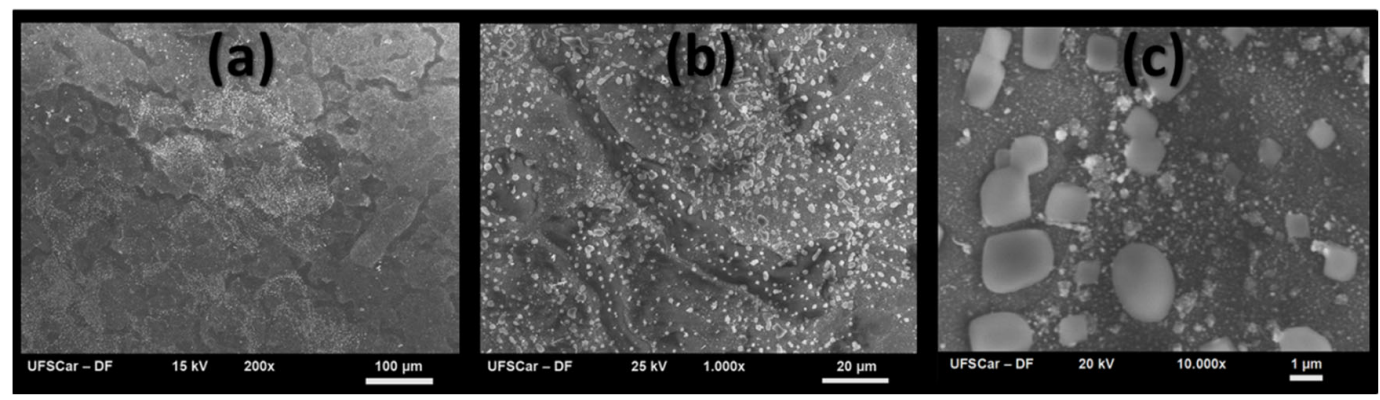

Figure 3. Scanning electron microscopy images show films with extended grooves (a) and the presence of small silver microcrystallites (b) with cubic structure (c).

High-resolution XPS was employed to analyze the chemical state of the Ag/AgO film surface. Figure $4 \mathrm{a}$ shows the Ag $3 \mathrm{~d}$ and $\mathrm{O} 1 \mathrm{~s}$ (Figure $4 \mathrm{~b}$ ) spectra. Figure $4 \mathrm{a}$ shows two strong sharp peaks at $367.98 \mathrm{eV}$ (with full width at half maximum-FWHM = $1.01 \mathrm{eV}$ ) and $373.98 \mathrm{eV}(\mathrm{FWHM}=1.12 \mathrm{eV})$ assigned to $\mathrm{Ag} 3 \mathrm{~d}_{5 / 2}$ and $\mathrm{Ag3} \mathrm{d}_{3 / 2}[13,28,29]$. The shape of these emissions is well-known and indicates the presence of $\mathrm{AgO}, \mathrm{Ag}_{2} \mathrm{O}$, and $\mathrm{Ag}$ on the surface. A slight asymmetry is observed at lower energies tail, and a careful fitting by CasaXPS software considered a 0.7 Gaussian/0.3 Lorentzian profile. To correct the asymmetry of the main metal peak, we employed the Lorentzian Assymetric (LA) tool which considers the spread of tails in the Lorentzian component and the width of Gaussian [30]. The main intense peaks with binding energies at $367.95 \mathrm{eV}$ and $373.97 \mathrm{eV}$ are assigned 
to metallic silver and the weaker emissions in lower binding energies at $367.42 \mathrm{eV}$ and $373.5 \mathrm{eV}$ to $\mathrm{Ag}^{2+}$ specimens. This unusual redshift of binding energies for $\mathrm{Ag}^{2+}$ is attributed to factors other than electronegativity differences between the metal atom and cation, such as lattice potential, work function changes, and extra-atomic relaxation energy [13,31]. Thus, together with the SEM images, the XPS results match metallic silver structures on the surface rather than embedded clustered Ag.

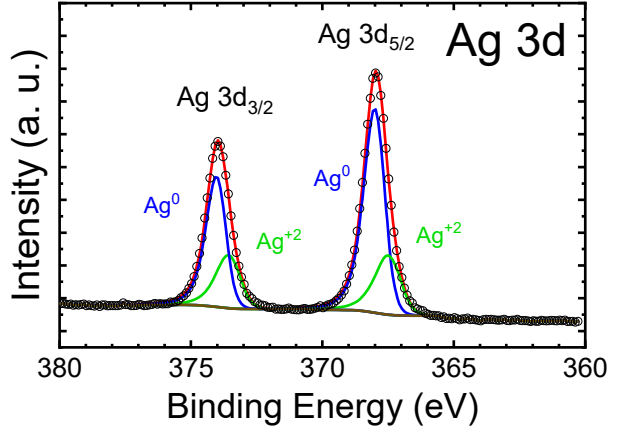

(a)

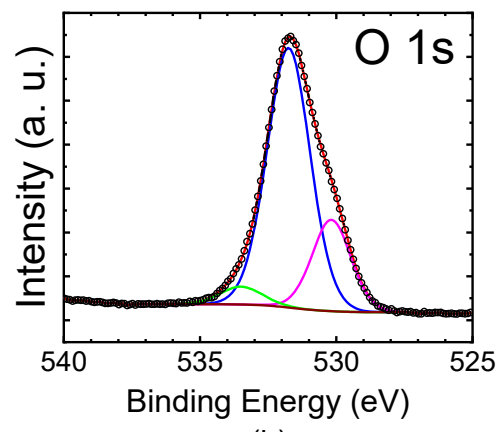

(b)

Figure 4. High-resolution XPS spectra. (a) Ag 3d spectra show the metallic character of the surface due to strong emission from $\mathrm{Ag}$ as compared to $\mathrm{Ag}^{2+}$. (b) $\mathrm{O} 1 \mathrm{~s}$ is a mixed-valence state signature associated with $\mathrm{AgO}$ film.

The peak shape of the $\mathrm{O} 1 \mathrm{~s}$ level centered at $531.68 \mathrm{eV}(\mathrm{FWHM}=2.50 \mathrm{eV})$ in Figure $4 \mathrm{~b}$ indicates that a single Gaussian-Lorentzian peak function cannot be applied to fit it. Therefore, the $\mathrm{O} 1 \mathrm{~s}$ level was deconvoluted into three splitting peaks. At higher energies and low percentage $(2.6 \%)$, the binding energy centered at $532.7 \mathrm{eV}$ is assigned to adsorption of oxygenated species as $\mathrm{C}=\mathrm{O}$ and $\mathrm{C}-\mathrm{OH}[13,32]$. The most intense binding energy $(76.2 \%)$ at $530.94 \mathrm{eV}$ is related to the binding to metal at +2 valence, which characterizes the formation of $\mathrm{AgO}$ [33]. Nevertheless, the non-negligible low energy tail implies a peak centered at $529.35 \mathrm{eV}$, associated with a mixed-valence state of the structurally equivalent oxygen atoms [34,35].

\subsection{Electro-Optical Characteristics}

Figure 5 exhibits the optical transmittance of $\mathrm{Ag} / \mathrm{AgO}$ film. The film has high transmittance in the infrared range $(\lambda>800 \mathrm{~nm})$ and a significant broad absorption centered at $500 \mathrm{~nm}$. This absorption is related to surface plasmon resonance (SPR) due to metallic Ag clusters $[3,36]$. It is worth noting a UV optical window centered at $330 \mathrm{~nm}(\mathrm{FWHM}=0.85 \mathrm{eV})$.

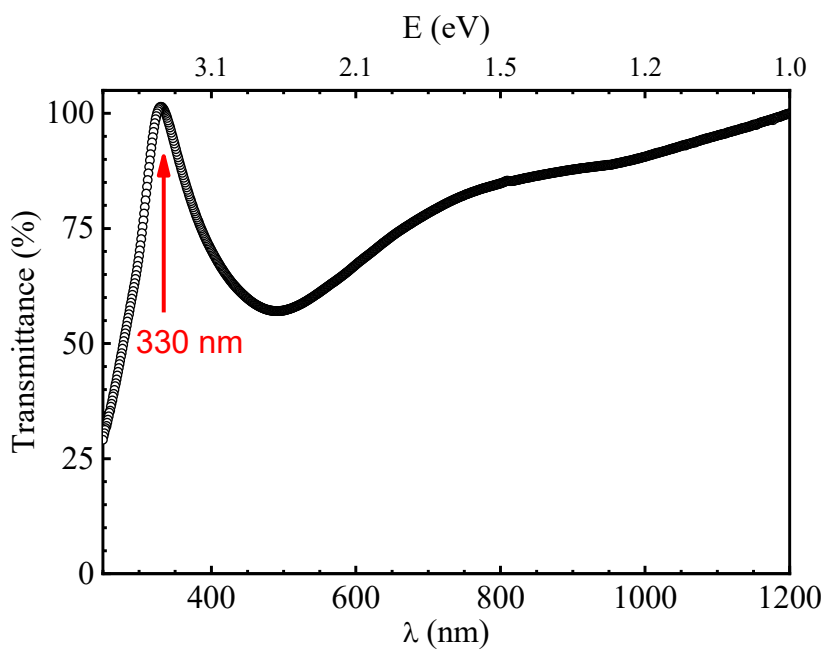

Figure 5. The optical transmittance through $\mathrm{Ag} / \mathrm{AgO}$ film shows characteristics of a UV window with the coexistence of optical effects due to metallic Ag, such as the SPR absorption around $500 \mathrm{~nm}$. 
The development of optical sensing devices is an exciting topic considering fundamental and applied physics. Optical stimulation in semiconductors usually promotes electrons from the valence band to the conduction band, which causes an increase in conductivity. The behavior observed in the $\mathrm{Ag} / \mathrm{AgO}$ film investigated in this work is the opposite. Figure 6 shows the relative photoresponse (PR), defined as

$$
\mathrm{PR}=\frac{\mathrm{R}_{\mathrm{D}}-\mathrm{R}}{\mathrm{I}_{\mathrm{LED}} \cdot \mathrm{R}_{\mathrm{D}}}
$$

where $R_{D}$ is the measured electrical resistance in the dark, $R$ under illumination, and $I_{L E D}$ is the normalized intensity of LED emissions in respect to the red one, correcting the PR for each wavelength excitation. For $\mathrm{Ag} / \mathrm{AgO}$ film, a substantial increase in resistance and a decrease in photoconductivity are measured for all wavelengths, from red to UV. After evaluating the dark resistance during $100 \mathrm{~s}$ (null photoresponse in Figure 6), the illuminated sample presents a fast response, in the order of seconds, consolidating a plateau. With its stabilization, the light is switched off, and the system recovers its initial condition after $15 \mathrm{~s}$. The critical ranges in Figure 6 are normalized to the plateau when the light is switched-on or switched-off. This procedure emphasizes the time dependence on wavelength excitation. However, it is worth noting that the recovery is not straightforward, presenting an additional step with the photoresponse above zero, indicating a decrease in electrical resistance. After a further time, the resistivity increases up to initial conditions again.

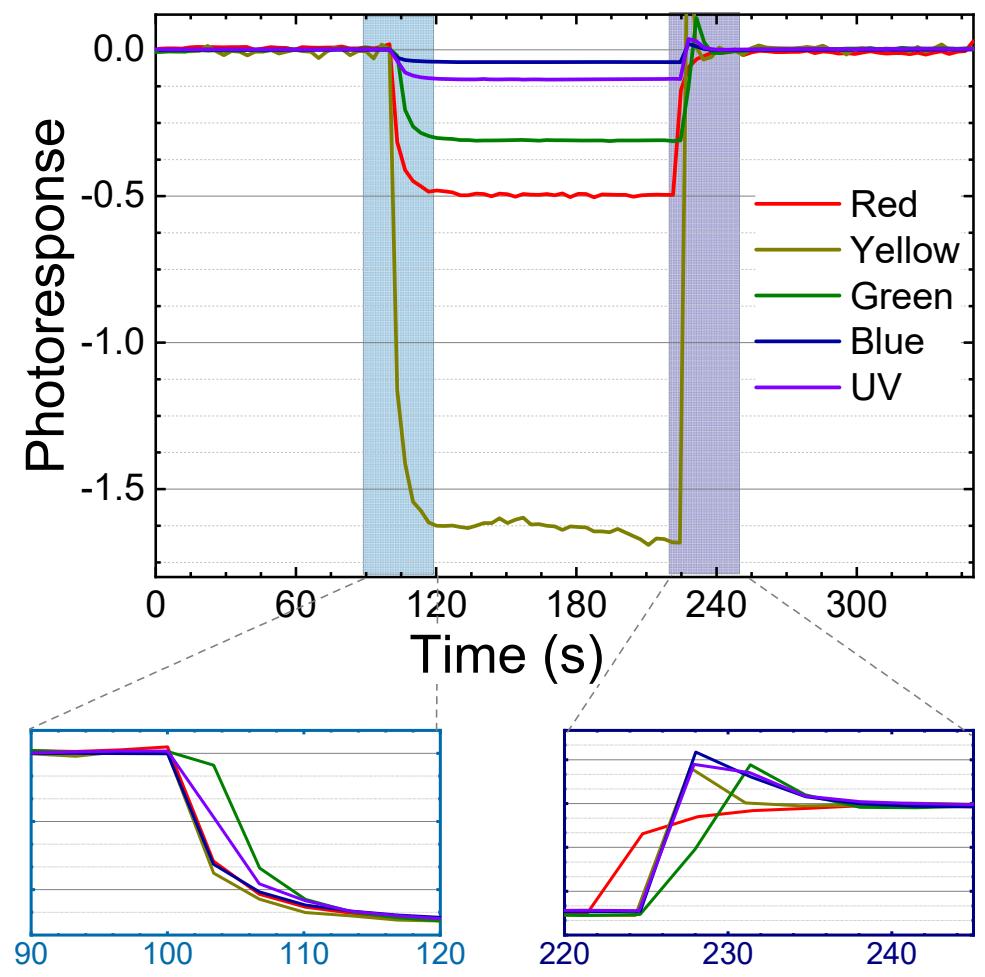

Figure 6. The transient photoconductivity response of $\mathrm{Ag} / \mathrm{AgO}$ film under illumination by several wavelengths exhibits negative behavior typical of defects presence. The normalization of the plateau in the crosshatched ranges evidences the issues related to response and recovery times depending on the wavelength excitation.

Negative photoconductivity (NPC) is attributed to shallow traps, acting as donor or acceptor states. In fact, any LED emission energies excite the AgO film directly. The photons seem to excite either the carrier from a band to a defect state or detrapping a defect state, which can then capture free carriers from the electronic bands [17]. From a qualitative point of view, the primary mechanism responsible for NPC is the ratio between 
recombination and generation rates in the presence of light [37]. The role of additional levels and/or bands on the photoconductivity mechanisms was previously modeled by Salis et al. [38] and recently by Paiva et al. [37] with a set of rate equations considering the presence of deep and shallow traps. The nature of shallow traps responsible for the negative photoconductivity in $\mathrm{AgO}$ requires further systematic investigations.

The strength of NPC is evaluated by comparing the plateau due to different excitations. As the energy increases, from the red to yellow excitations, around $2.0 \mathrm{eV}$, the NPC exhibits a substantial boost with faster response times (Figure 7a,b). Despite low optical absorbance of film, photons act to liberate charge from traps that capture the free carriers of AgO. In contrast, in the range of green illumination, the strong optical absorbance by SPR affects the NPC, and the negative photoresponse declines substantially. Furthermore, response times increase with the LED energy (lower wavelengths). For UV illumination, with the highest energy but below the AgO bandgap, the response time is more than 5 sec with a low negative PR. The silver particles, responsible for the additional absorption in localized states, do not contribute to electrical behavior.

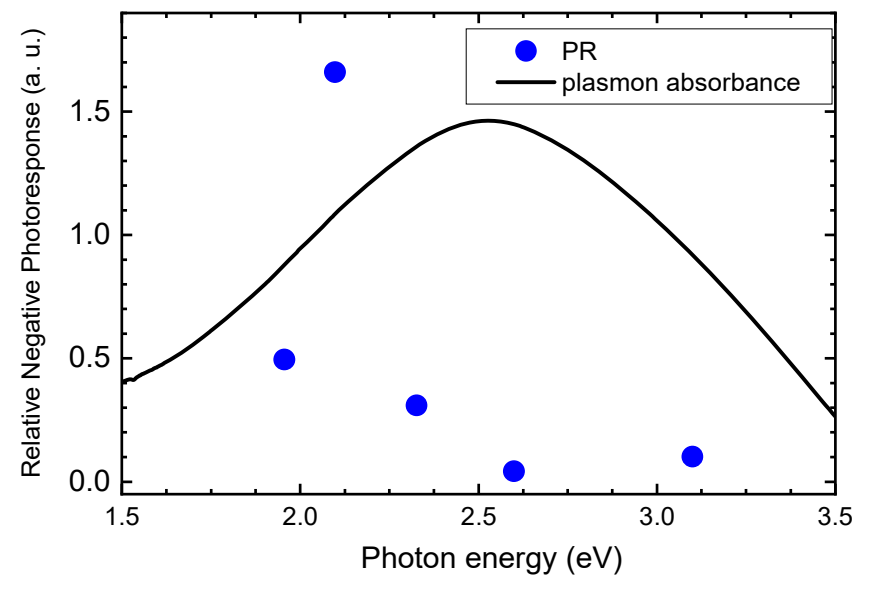

(a)

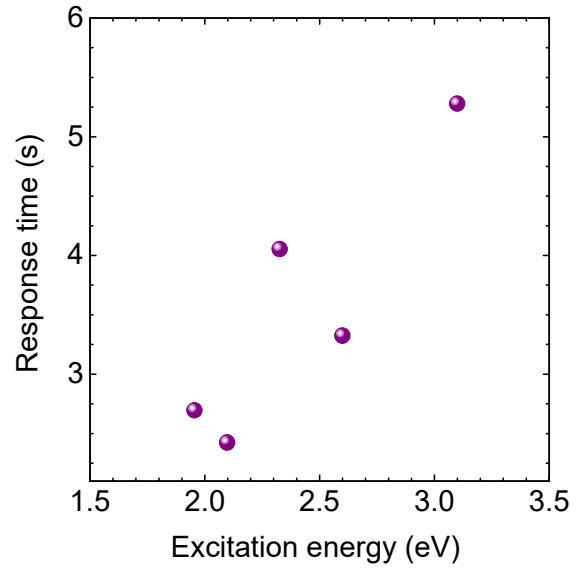

(b)

Figure 7. Comparison between photoconductivity behavior for different excitations. (a) The negative photoconductivity decreases when the excitation energy is near the surface plasmon resonance from Ag clusters measured by optical absorbance. (b) The response times present a systematic increase when LED energies rise.

\section{Conclusions}

Spray pyrolysis emerges as a suitable technique to grow Ag-decorated AgO thin films. Our results indicate that the negative photoresponse observed for $\mathrm{Ag} / \mathrm{AgO}$ film is dependent on two factors: shallow traps in the electronic structure of the AgO phase and the presence of metallic Ag acting as an additional absorber center.

Author Contributions: Conceptualization, A.B.d.P., M.L.P. and M.P.F.d.G.; methodology, A.B.d.P., M.L.P. and M.P.F.d.G.; validation, A.B.d.P., A.D.G.R., M.L.P. and M.P.F.d.G.; formal analysis, A.B.d.P., A.D.G.R., M.L.P. and M.P.F.d.G.; investigation, A.B.d.P., L.M.B.V. and M.J.d.S.; resources, D.A.W.S., M.L.P. and M.P.F.d.G.; data curation, A.B.d.P., L.M.B.V. and M.P.F.d.G.; writing-original draft preparation, A.B.d.P. and M.P.F.d.G.; writing—review and editing, A.D.G.R., M.L.P., D.A.W.S. and M.P.F.d.G.; supervision, M.L.P. and M.P.F.d.G.; project administration A.D.G.R., D.A.W.S., M.L.P. and M.P.F.d.G. All authors have read and agreed to the published version of the manuscript.

Funding: This research was partialy funded by Conselho Nacional de Desenvolvimento Científico e Tecnológico-CNPq (grant 309230/2020-9). A.B.d.P also thanks CNPq for her PhD fellowship (141636/2018-1) and L.M.B. Vargas acknowledges CAPES for his PhD fellowship.

Institutional Review Board Statement: Not applicable.

Informed Consent Statement: Not applicable. 
Data Availability Statement: Not applicable.

Acknowledgments: This research used facilities of the Brazilian Nanotechnology National Laboratory (LNNano), part of the Brazilian Centre for Research in Energy and Materials (CNPEM), a private non-profit organization under the supervision of the Brazilian Ministry for Science, Technology, and Innovations (MCTI). The XPS staff is acknowledged for their assistance during the experiments (proposal XPS-24720). In addition, technical support from Natalia Zanardi and Roberto Sabadini is gratefully recognized.

Conflicts of Interest: The authors declare no conflict of interest.

\section{References}

1. Onofre, Y.J.; Catto, A.C.; Bernardini, S.; Fiorido, T.; Aguir, K.; Longo, E.; Mastelaro, V.R.; da Silva, L.F.; de Godoy, M.P.F. Highly selective ozone gas sensor based on nanocrystalline $\mathrm{Zn} 0.95 \mathrm{Co} 0.05 \mathrm{O}$ thin film obtained via spray pyrolysis technique. Appl. Surf. Sci. 2019, 478, 347-354. [CrossRef]

2. Akhtar, M.; Umar, A.; Sood, S.; Jung, I.; Hegazy, H.; Algarni, H. Rapid Growth of TiO2 Nanoflowers via Low-Temperature Solution Process: Photovoltaic and Sensing Applications. Materials 2019, 12, 566. [CrossRef]

3. Cattabiani, N.; Baratto, C.; Zappa, D.; Comini, E.; Donarelli, M.; Ferroni, M.; Ponzoni, A.; Faglia, G. Tin Oxide Nanowires Decorated with Ag Nanoparticles for Visible Light-Enhanced Hydrogen Sensing at Room Temperature: Bridging Conductometric Gas Sensing and Plasmon-Driven Catalysis. J. Phys. Chem. C 2018, 122, 5026-5031. [CrossRef]

4. Kim, M.; Lin, M.; Son, J.; Xu, H.; Nam, J.-M. Hot-Electron-Mediated Photochemical Reactions: Principles, Recent Advances, and Challenges. Adv. Opt. Mater. 2017, 5, 1700004. [CrossRef]

5. Li, J.; Tao, Y.; Chen, S.; Li, H.; Chen, P.; Wei, M.; Wang, H.; Li, K.; Mazzeo, M.; Duan, Y. A flexible plasma-treated silver-nanowire electrode for organic light-emitting devices. Sci. Rep. 2017, 7, 16468. [CrossRef] [PubMed]

6. Watté, J.; van Zele, M.; de Buysser, K.; van Driessche, I. Recent Advances in Low-Temperature Deposition Methods of Transparent, Photocatalytic TiO2 Coatings on Polymers. Coatings 2018, 8, 131. [CrossRef]

7. Fantoni, A.; Fernandes, M.; Vygranenko, Y.; Louro, P.; Vieira, M.; Silva, R.P.O.; Texeira, D.; Ribeiro, A.P.C.; Prazeres, M.; Alegria, E.C.B.A. Analysis of metallic nanoparticles embedded in thin film semiconductors for optoelectronic applications. Opt. Quantum Electron. 2018, 50, 246. [CrossRef]

8. Cortial, G.; Siutkowski, M.; Goettmann, F.; Moores, A.; Boissière, C.; Grosso, D.; le Floch, P.; Sanchez, C. Metallic Nanoparticles Hosted in Mesoporous Oxide Thin Films for Catalytic Applications. Small 2006, 2, 1042-1045. [CrossRef] [PubMed]

9. Brady, B.; Wang, P.H.; Steenhoff, V.; Brolo, A.G. Nanostructuring Solar Cells Using Metallic Nanoparticles. In Metal Nanostructures for Photonics; Elsevier: Amsterdam, The Netherlands, 2019; pp. 197-221.

10. Naghdi, S.; Rhee, K.; Hui, D.; Park, S. A Review of Conductive Metal Nanomaterials as Conductive, Transparent, and Flexible Coatings, Thin Films, and Conductive Fillers: Different Deposition Methods and Applications. Coatings 2018, 8, 278. [CrossRef]

11. Morales, J.; Sánchez, L.; Martín, F.; Ramos-Barrado, J.R.; Sánchez, M. Synthesis, Characterization, and Electrochemical Properties of Nanocrystalline Silver Thin Films Obtained by Spray Pyrolysis. J. Electrochem. Soc. 2004, 151, A151. [CrossRef]

12. Waterhouse, G.I.N.; Bowmaker, G.A.; Metson, J.B. The thermal decomposition of silver (I, III) oxide: A combined XRD, FT-IR and Raman spectroscopic study. Phys. Chem. Chem. Phys. 2001, 3, 3838-3845. [CrossRef]

13. Vidyasagar, D.; Ghugal, S.G.; Kulkarni, A.; Mishra, P.; Shende, A.G.; Jagannath; Umare, S.S.; Sasikala, R. Silver/Silver(II) oxide $(\mathrm{Ag} / \mathrm{AgO})$ loaded graphitic carbon nitride microspheres: An effective visible light active photocatalyst for degradation of acidic dyes and bacterial inactivation. Appl. Catal. B Environ. 2018, 221, 339-348. [CrossRef]

14. Fortin, E.; Weichman, F.L. Photoconductivity in $\mathrm{Ag}_{2}$ O. Phys. Status Solidi. 1964, 5, 515-519. [CrossRef]

15. Lee, T.H.; Hladik, C.R.; Dickson, R.M. Asymmetric Photoconductivity within Nanoscale Break Junctions. Nano Lett. 2003, 3, 1561-1564. [CrossRef]

16. Yang, Y.; Peng, X.; Kim, H.S.; Kim, T.; Jeon, S.; Kang, H.K.; Choi, W.; Song, J.; Doh, Y.J.; Yu, D. Hot Carrier Trapping Induced Negative Photoconductance in InAs Nanowires toward Novel Nonvolatile Memory. Nano Lett. 2015, 15, 5875-5882. [CrossRef] [PubMed]

17. Tavares, M.A.B.; da Silva, M.J.; Peres, M.L.; de Castro, S.; Soares, D.A.W.; Okazaki, A.K.; Fornari, C.I.; Rappl, P.H.O.; Abramof, E. Investigation of negative photoconductivity in p-type Pb1-xSnxTe film. Appl. Phys. Lett. 2017, 110, 042102. [CrossRef]

18. Ianhez-Pereira, C.; Onofre, Y.J.; Magon, C.J.; Rodrigues, A.D.; de Godoy, M.P.F. The interplay between Mn valence and the optical response of $\mathrm{ZnMnO}$ thin films. Appl. Phys. A 2020, 126, 337. [CrossRef]

19. de Godoy, M.P.F.; de Herval, L.K.S.; Cotta, A.A.C.; Onofre, Y.J.; Macedo, W.A.A. ZnO thin films design: The role of precursor molarity in the spray pyrolysis process. J. Mater. Sci. Mater. Electron. 2020, 31, 17269-17280. [CrossRef]

20. Cullity, S.R.; Stock, B.D. Elements of X-ray Diffraction, 3rd ed.; Prentice-Hall: New York, NY, USA, 2001.

21. Ramadan, R.; Dadgostar, S.; Silván, M.M.; Pérez-Casero, R.; Hernandez-Velez, M.; Jimenez, J.; Sanchez, O. Silver-enriched ZnO:Ag thin films deposited by magnetron co-sputtering: Post annealing effects on structural and physical properties. Mater. Sci. Eng. B 2022, 276, 115558. [CrossRef]

22. Dun, A.; Wei, J.; Gan, F. Pattern structures fabricated on $\mathrm{ZnS}-\mathrm{SiO} 2 / \mathrm{AgO}$ x/ZnS-SiO2 thin film structure by laser direct writing technology. Appl. Phys. A Mater. Sci. Process. 2010, 100, 401-407. [CrossRef] 
23. Meškinis, ̌̌.; Čiegis, A.; Vasiliauskas, A.; Tamulevičiene, A.; Šlapikas, K.; Juškenas, R.; Niaura, G.; Tamulevičius, S. Plasmonic properties of silver nanoparticles embedded in diamond like carbon films: Influence of structure and composition. Appl. Surf. Sci. 2014, 317, 1041-1046. [CrossRef]

24. Jaiswal, K.K.; Banerjee, I.; Dutta, S.; Verma, R.; Gunti, L.; Awasthi, S.; Bhushan, M.; Kumar, V.; Alajmi, M.F.; Hussain, A. Microwave-assisted polycrystalline $\mathrm{Ag} / \mathrm{AgO} / \mathrm{AgCl}$ nanocomposites synthesis using banana corm (rhizome of Musa sp.) extract: Characterization and antimicrobial studies. J. Ind. Eng. Chem. 2021, 107, 145-154. [CrossRef]

25. Raju, N.R.C.; Kumar, K.J.; Subrahmanyam, A. Physical properties of silver oxide thin films by pulsed laser deposition: Effect of oxygen pressure during growth. J. Phys. D Appl. Phys. 2009, 42, 135411. [CrossRef]

26. Vargas, L.M.; de Castro, S.; Peres, M.L.; de Godoy, M.P.; Soares, D.A. Soares, Tuning positive and negative photoconductivity in Zn 1-x Cd x O. films. J. Alloys Compd. 2018, 749, 734-740. [CrossRef]

27. Onofre, Y.J.; de Castro, S.; Rodrigues, A.D.; de Godoy, M.P.F. Influence of Co-doping on optical properties and traps localization of ZnO films obtained by spray pyrolysis. J. Anal. Appl. Pyrolysis 2017, 128, 131-135. [CrossRef]

28. Bartosewicz, B.; Liszewska, M.; Budner, B.; Michalska-Domańska, M.; Kopczyński, K.; Jankiewicz, B.J. Fabrication of Ag-modified hollow titania spheres via controlled silver diffusion in $\mathrm{Ag}-\mathrm{TiO}_{2}$ core-shell nanostructures, Beilstein. J. Nanotechnol. 2020, 11, 141-146. [CrossRef]

29. Wei, W.; Mao, X.; Ortiz, L.A.; Sadoway, D.R. Oriented silver oxide nanostructures synthesized through a template-free electrochemical route. J. Mater. Chem. 2011, 21, 432-438. [CrossRef]

30. Biesinger, M.C.; Payne, B.P.; Lau, L.W.M.; Gerson, A.; Smart, R.S.C. X-ray photoelectron spectroscopic chemical state Quantification of mixed nickel metal, oxide and hydroxide systems. Surf. Interface Anal. 2009, 41, 324-332. [CrossRef]

31. Weaver, J.F.; Hoflund, G.B. Surface Characterization Study of the Thermal Decomposition of AgO. J. Phys. Chem. 1994, 98, 8519-8524. [CrossRef]

32. Murray, B.J.; Li, Q.; Newberg, J.T.; Hemminger, J.C.; Penner, R.M. Silver oxide microwires: Electrodeposition and observation of reversible resistance modulation upon exposure to ammonia vapor. Chem. Mater. 2005, 17, 6611-6618. [CrossRef]

33. Wu, L.Q.; Li, Y.C.; Li, S.Q.; Li, Z.Z.; Tang, G.D.; Qi, W.H.; Xue, L.C.; Ge, X.S.; Ding, L.L. Method for estimating ionicities of oxides using O1s photoelectron spectra. AIP Adv. 2015, 5, 097210. [CrossRef]

34. Bielmann, M.; Schwaller, P.; Ruffieux, P.; Gröning, O.; Schlapbach, L.; Gröning, P. AgO investigated by photoelectron spectroscopy: Evidence for mixed valence. Phys. Rev. B Condens. Matter Mater. Phys. 2002, 65, 1-5. [CrossRef]

35. Tjeng, L.H.; Meinders, M.B.J.; van Elp, J.; Ghijsen, J.; Sawatzky, G.A.; Johnson, R.L. Electronic structure of Ag 2 O. Phys. Rev. B 1990, 41, 3190-3199. [CrossRef] [PubMed]

36. Liu, X.; Li, D.; Sun, X.; Li, Z.; Song, H.; Jiang, H.; Chen, Y. Tunable Dipole Surface Plasmon Resonances of Silver Nanoparticles by Cladding Dielectric Layers. Sci. Rep. 2015, 5, 1-7. [CrossRef] [PubMed]

37. de Paiva, A.B.; Correr, G.I.; Ugucioni, J.C.; Carvalho, G.R.; Jasinevicius, R.G.; de Godoy, M.P.F. On the photoconductivity behavior of emeraldine-salt polyaniline films. Synth. Met. 2021, 281, 116915. [CrossRef]

38. Salis, M.; Anedda, A.; Quarati, F.; Blue, A.J.; Cunningham, W. Photocurrent in epitaxial GaN. J. Appl. Phys. 2005, 97, 033709. [CrossRef] 